\title{
Being lean: how to shape digital transformation in the manufacturing sector
}

\author{
Matteo Rossini, Fabiana Dafne Cifone, Bassel Kassem, Federica Costa \\ and Alberto Portioli-Staudacher \\ Department of Management, Economics and Industrial Engineering, \\ Politecnico di Milano, Milan, Italy
}

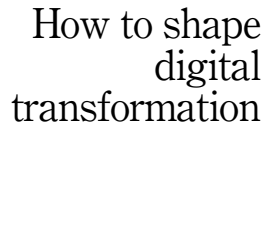

239

Received 2 December 2020 Revised 30 March 2021 Accepted 2 May 2021

\begin{abstract}
Purpose - Industry 4.0 and Lean Production are a successful match in terms of performance improvement. While we understand the combined potential, there is still poor understanding of how companies should embrace digital transformation to make it successful and sustainable, and the role that lean plays in it. In this paper, we investigate how manufacturing companies embark upon digital transformation and how being lean might affect it.

Design/methodology/approach - We conducted multiple case studies with 19 manufacturing companies. We identified two clusters of companies according to their Lean maturity, and we assessed digital transformation patterns by analyzing insights coming both from cases and from the literature. Integrating cross-case analysis results, we developed a framework that shows two different digital transformation patterns according to companies' commitment to Lean.

Findings - Our findings first and foremost show the significant role of lean in driving digital transformation. We identify two patterns, namely Sustaining digital transformation pattern, characterized by the pervasive role of lean culture with small and horizontal digital changes, involvement of people and willingness to maintain continuous process improvement, and Disruptive digital transformation pattern, characterized by few and large digital steps that imply a disruptive and radical change in the company system.

Practical implications - Empirical evidence supports the relevance of the proposed model and its practical usefulness. It can be used to design digital transformation, prepare properly the introduction of Industry 4.0 through a lean approach, and plan the future desired state, identifying the Industry 4.0 technologies that should be implemented.

Originality/value - It is widely recognized that the relationship between Industry 4.0 and lean is significant and positive, yet little evidence was presented to back that. We aim at bringing this debate forward by providing initial empirical evidence of the significant role that lean has on digital transformation, showing how lean drives the digital transformation pattern of companies.
\end{abstract}

Keywords Digital transformation, Lean, Industry 4.0

Paper type Research paper

\section{Introduction}

Industry 4.0 (I4.0) is increasingly in the spotlight of researchers, economic policymakers and manufacturers (Brennan et al., 2015; Frank et al., 2019; Rossini et al., 2019b). It is built upon inter-connected machines, intelligent systems and products, inter-related solutions within a company (Koh et al., 2019; Sanders et al., 2017; Tortorella and Fettermann, 2018) and enhanced human-machine interaction (Liao et al., 2017; Sanders et al., 2016). I4.0 involves integrated digital technologies implementation, which facilitates monitoring and controlling

(C) Matteo Rossini, Fabiana Dafne Cifone, Bassel Kassem, Federica Costa and Alberto PortioliStaudacher. Published by Emerald Publishing Limited. This article is published under the Creative Commons Attribution (CC BY 4.0) licence. Anyone may reproduce, distribute, translate and create derivative works of this article (for both commercial and non-commercial purposes), subject to full attribution to the original publication and authors. The full terms of this licence may be seen at http:// creativecommons.org/licences/by/4.0/legalcode

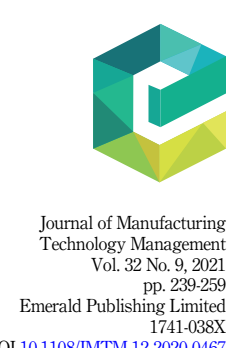

DOI 10.1108/JMTM-12-2020-0467 
JMTM 32,9

of physical devices, sensors, information and communication technologies, and Industrial Internet of Things applications (Lasi et al., 2014; Quezada et al., 2017). The set and the sequence of I4.0 technologies implementations define the digital transformation of a company (Culot et al., 2020). Despite a growing number of research contributions on the I4.0 topic (Benitez et al., 2020; Frank et al., 2019; Tortorella et al., 2019), companies are struggling with understanding how digital transformation should occur (Erol et al., 2016; Sanders et al., 2016, 2017). The risk companies are facing is to start an ineffective digital transformation that is not built upon their characteristics but only driven by the I4.0 hype. This risk becomes even greater if we consider that several countries such as Brazil, India, Mexico and Italy launched governmental initiatives to incentivize companies toward digital transformation (Forbes India, 2020; National Confederation of Industry, 2016; Mexican Ministry of Economy, 2016). To benefit from the aforementioned governmental incentives, companies may take random initiatives without really considering their characteristics and needs. The absence of proper guidelines or patterns makes thus the success of companies' digital transformation uncertain.

Scientific literature highlights that the companies adopting Lean Production (LP) are a fertile environment for successful digital transformation (Rossini et al., 2019b; Tortorella et al., 2019) and that LP is an enabler for digital transformation through directing I4.0 technologies toward its tools and practices (Ghobakhloo and Fathi, 2020; Pagliosa et al., 2019). While the discussion about integration between I4.0 and LP system received growing attention among practitioners and academicians (Buer et al., 2018; Rossini et al., 2019b), researches are mainly focused either on specific technologies or performance improvement achieved by single digital technology implementation (Gillani et al., 2020; Wagner et al., 2017). It is still unclear whether and how the intrinsic characteristics of LP may influence a specific digital transformation. Therefore, we seek to cover this research gap by responding to the following research question:

$R Q$. Does being lean affect how companies are shaping their digital transformation?

Since the novelty of the topic, and the lack of empirical study on how companies embark upon digital transformation, and on the role played by LP in it, we carry out exploratory case studies. We analyzed 19 companies belonging to the manufacturing industry (Voss et al., 2002), either highly committed to LP or poorly committed to LP, through the following four areas: adopted I4.0 technologies, drivers for I4.0 investments, the magnitude of I4.0 investments, and people and I4.0. The scope is to unveil potential similarities or differences among the two clusters of companies and to understand whether LP is a critical element for digital transformation.

Our findings support the theoretical view of LP playing a strong role in driving digital transformation. This research contributes to the conceptual debate of advanced manufacturing technology and operational excellence by providing initial empirical evidence of how LP and its culture may affect companies' digital transformation. Our findings also have direct managerial implications since companies' financial resources are often scarce, and their I4.0 technologies implementation must be well-informed by studies like ours.

This paper is structured as follows: after the introduction, Section 2 provides the theoretical background our paper is built on. Section 3 explains the case study research methods, while in Section 4, we provide our main findings. In Section 5, we discuss the two resulting digital transformation patterns, and eventually, in the final section, we conclude with the contribution and limitations of our research, also providing avenues for future research.

\section{Theoretical background}

According to the scope of the research, we review the literature on the existing relationship between I4.0 and LP. Researchers state that the implementation of both paradigms in a 
manufacturing company contributes to improving its operational performances (Kolberg and Zühlke, 2015; Moeuf et al., 2018). Several studies suggest that combining I4.0 and LP increases productivity (Sanders et al., 2016), flexibility (Kolberg and Zühlke, 2015), or reliability (Wagner et al., 2017). More in general, Dombrowski and Richter (2018) state that LP practices are positively associated with I4.0 technologies, and their concurrent implementation leads to larger performance improvements.

The literature stresses more the support I4.0 has on LP (e.g. Kolberg and Zühlke, 2015; Lugert et al., 2018; Rosin et al., 2020), rather than how LP may affect digital transformation (e.g. Buer et al., 2018; Hambach et al., 2017). It addresses mostly the possibilities included in the paradigm of I4.0 that serve in digitalizing LP practices (Chiarini et al., 2020). For example, Sanders et al. $(2016,2017)$ conclude that most I4.0 technologies play a supportive role in regard to LP practices by creating a theoretically based interdependence matrix. Similar results have been achieved by Wagner et al. (2017) and by Mayr et al. (2018). In general terms, there is consensus that I4.0 technologies, such as Industrial Internet of Things, Cloud manufacturing, Industrial Analytics and Advanced automation, mostly improve LP practices such as continuous flow, visual management, eyes for waste, in-station quality control and kanban system (Rosin et al., 2020).

Digital transformation is delineated by the type and the sequence of I4.0 technologies implemented, as well as in which area of the company (Culot et al., 2020). It is the key enabler for competitive advantage in the I4.0 era (Buer et al., 2020), ensuring significant gains in manufacturing goals from productivity to costs, quality and flexibility (Pessot et al., 2020). These gains are much higher when adopting several technologies simultaneously instead of just one technology (Alcácer and Cruz-Machado, 2019). Rosin et al. (2020) identify four capability levels for I4.0 technologies that "are incremental and are based on each previous level": Monitoring (monitor in real-time or quasi-real-time production, maintenance, safety indicators), Control (based on data history, standard system behavior and expected performance, algorithms can be used to detect abnormal situations), Optimization (set of algorithms to optimize performances, recourses or efficiency), Autonomy (highest level of capability to react optimally and in real-time to a change in need). In the context of operations, Buer et al. (2020) focused on three main areas for the digital transformation and the technologies characterizing them: shop floor, vertical and horizontal integration, and organizational IT competence. The process of adopting I4.0 technologies in manufacturing companies requires financial and organizational readiness. Regarding financial investments, while not being challenging for large companies, SMEs are usually not early adopters mainly "because of the fear of investing in the wrong technologies or adopting inapt practices" (Mittal et al., 2018). On the other hand, organizations should be ready not only in terms of skills sculpting (Matt et al., 2015) but also in terms of adapting to the evolution that technologies will face continuously in the factory of the future (Pessot et al., 2020). Such researchers do not connect the dots between the organizational culture of the company and the process of digital transformation: Ghobakhloo and Fathi (2020) conducted a 5-year case study on the digital transformation of a manufacturing company, describing it as lean-digitized manufacturing. However, they follow the same stream of thought of most of the literature that talks about digitalizing LP tools and practices and how we can benefit from improving the performances. To the best of the authors' knowledge, the company's culture and its potential impact on digital transformation have been scarcely discussed.

LP is a culture on its own, and it is considered an enabler for I4.0; therefore, companies should exploit it to create a proper foundation for their digital transformation (Davies et al., 2017; Dombrowski and Richter, 2018; Prinz et al., 2018). The idea is that an effective digital transformation will take place within a context with streamlined flows, standardized processes and without wastes (Buer et al., 2018; Sony, 2018). Furthermore, a company that already embraces LP is more likely to exploit I4.0 (Rossini et al., 2019a; Tortorella et al., 2019).
How to shape digital

transformation 
JMTM 32,9

LP acts as a prerequisite for a successful digital transformation (Rossini et al., 2019a, b). The discussion is still ongoing as a risk the company might face is to randomly embrace the digital transformation that does not fit with its culture, which is being lean. Although there are some attempts to provide insights about how being LP may affect digital transformation, we are still far away from closing the debate.

In this research, we strive to cover this gap, namely, to investigate how companies embark upon digital transformation and whether being lean represents a contributing factor in driving it. More in detail, we seek to understand whether and how LP plays a role in shaping companies' digital transformation. The scope is limited to manufacturing companies, being the traditional context for lean. To this effect, we design a case study-based research in the Italian manufacturing sector presented hereafter.

\section{Case study method}

In this section, we present our case study-based research (resumed in Figure 1). First, we will describe the design of case studies and how we select the sample companies. Then, we explain their execution, as well as the analysis of data collected.

\subsection{Research design and case selection}

Due to the novelty of the topic and the lack of empirical proof in the scientific literature on how companies shape their digital transformation and on whether, and in case how, LP plays a role in that, we decided to further investigate using exploratory case studies, with the company as the unit of analysis. Indeed, case study-based research is widely used in operations management scope to generally develop and extend theory (Ketokivi and Choi, 2014; Netland and Ferdows, 2016; Voss et al., 2002) and to implement an inductive methodology (Gioia et al., 2013). Moreover, according to Yin (2014), this method is suitable when researchers need to consider several variables of interest and when new phenomena are under analysis. For all these reasons, case study-based research particularly fits our goal.

To ensure homogeneity and content validity, we performed the initial selection to control extraneous factors limiting the presence of differentiating factors (Eisenhardt, 1989). Purposely, we focused on companies working with low-volume and high-variety portfolios within one single country (Italy) and belonging only to the manufacturing industry (producers of machinery and metal products). This choice is in line with other studies within operations management scope (e.g. Cagliano et al., 2019): indeed, country legislation and policies, as well as industry and production strategies, may affect both LP and digital transformation choices.

We adopted a funnel logic to select the sample of companies to be included in our study. Our starting database included 85 different companies, which were already involved in past research (reference omitted for peer review), and are compliant with the aforementioned characteristics and knowledgeable of the two paradigms. First, we contacted them via email for their willingness to be involved in the study, and 19 companies responded positively, equal to $22.3 \%$ of the starting dataset. To assess the LP level of these companies, we asked them to self-evaluate their LP maturity level through the assessment developed by Shah and Ward (2007). The self-assessment consisted of a survey of 41 questions (Shah and Ward, 2007) provided via email, where companies were required to evaluate through a 5-point Likert scale the extent of LP practices implementation within their belonging company.

To unveil the presence of different levels of LP maturity, we performed a two-step cluster analysis using $R$ software (Rossini et al., 2019b; Tortorella and Fettermann, 2018). Companies grouped within each cluster should indeed show similar features in terms of lean level implementation to the ones belonging to the same cluster and different characteristics from 

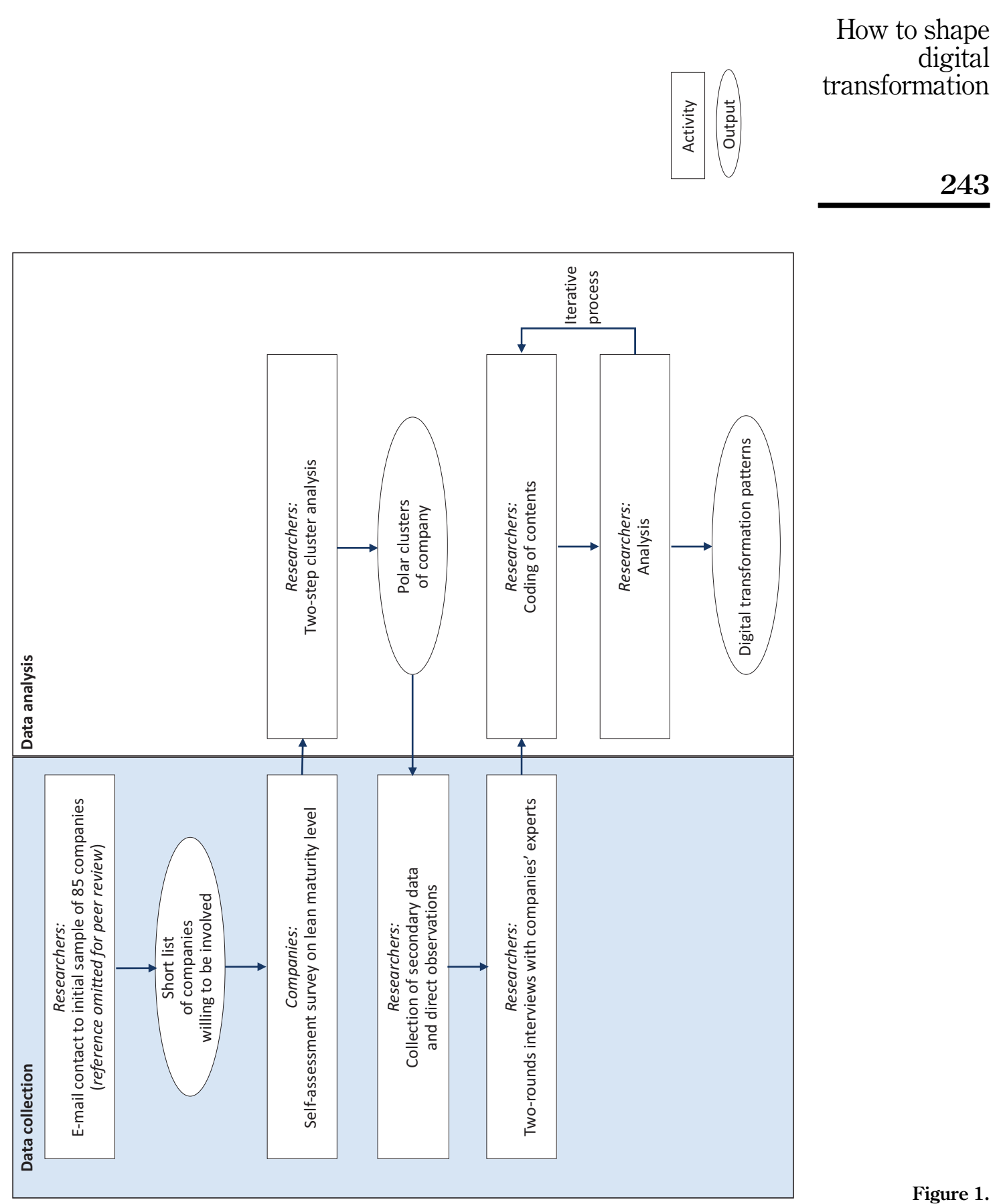

Figure 1. Research methodology 
JMTM 32,9

\section{4}

the ones belonging to other clusters (Rencher and William, 2012). We implemented Ward's method with both Euclidean and Manhattan distances to compute the optimal number of clusters $(k)$, double-checking results also with Elbow and the Silhouette methods. The resulted $k$ is two. Then, we used the $K$-means clustering method to properly group our 19 companies within clusters, assessing the consistency and homogeneity of them through the Cohesion index and Silhouette coefficient. The results enabled the identification of the presence of two polar clusters of companies. We decided to include all 19 companies within our final sample and conduct two embedded case studies, specifically one per each polar cluster.

One cluster (Cluster A) includes 10 companies that register a high level of implementation of LP practices. These companies show a strategic commitment to LP and an extensive implementation of practices. The other cluster (Cluster B) includes nine companies, with a low level of implementation of LP practices. These companies lack a commitment to LP and apply its practices poorly.

\subsection{Execution}

Consistent with the use of multiple data collection in case study based research, data are collected through multiple sources: secondary data as official documents, direct observation and semi-structured interviews with reference people (Bryman, 2012). To guarantee the reliability of the cases, we sought specific expertise in respondents for every company: experts were required to be involved in both LP and digital transformation projects. We targeted one person per company, holding titles such as managers, head of operations, or Kaizen Promotion Officer, as shown in Table 1.

The interview protocol, available in Appendix, is structured into five macro areas: (1) background of the interviewee and the company, (2) decision process on I4.0, (3) I4.0 technologies adopted, (4) rationale behind I4.0 investments, (5) relationship between I4.0

and LP. Two-round interviews were carried out with each expert on-site by at least two

\begin{tabular}{|c|c|c|c|c|c|}
\hline & Case & Company & $\begin{array}{l}\text { Industrial sector } \\
\text { (M = Machinery; } \\
\text { MP = Metal products) }\end{array}$ & Size $(\mathrm{mln} €)$ & Interviewee role \\
\hline & $\mathrm{A}$ & 1 & MP & 236.2 & Production Manager \\
\hline & $\mathrm{A}$ & 13 & $\mathrm{M}$ & 186 & Manufacturing Manager \\
\hline & $\mathrm{A}$ & 15 & $\mathrm{M}$ & 136.1 & Production and Maintenance Manager \\
\hline & $\mathrm{A}$ & 12 & MP & 104.9 & Value Stream Coach \\
\hline & $\mathrm{A}$ & 14 & $\mathrm{M}$ & 86.2 & Lean Manager \\
\hline & $\mathrm{A}$ & 17 & $\mathrm{M}$ & 83.7 & Plant Manager \\
\hline & $\mathrm{A}$ & 5 & $\mathrm{M}$ & 83.2 & Supply Chain and Production Manager \\
\hline & $\mathrm{A}$ & 4 & $\mathrm{M}$ & 77.7 & Chief Operating Officer \\
\hline & $\mathrm{A}$ & 2 & $\mathrm{M}$ & 60.9 & Chief Executive Officer \\
\hline & $\mathrm{A}$ & 8 & $\mathrm{M}$ & 22.4 & Kaizen Promotion Officer \\
\hline & $\mathrm{B}$ & 7 & $\mathrm{M}$ & 818.5 & Chief Operating Officer \\
\hline & $\mathrm{B}$ & 10 & MP & 242 & Operational Excellence Manager \\
\hline & $\mathrm{B}$ & 16 & $\mathrm{M}$ & 209.2 & Production Manager \\
\hline & $\mathrm{B}$ & 18 & $\mathrm{M}$ & 143.5 & Production Manager \\
\hline & $\mathrm{B}$ & 3 & $\mathrm{M}$ & 127.7 & Operational Excellence Manager \\
\hline & $\mathrm{B}$ & 19 & $\mathrm{M}$ & 112.4 & Supply Chain Manager \\
\hline & $\mathrm{B}$ & 11 & $\mathrm{M}$ & 64.2 & Production Manager \\
\hline Table 1. & $\mathrm{~B}$ & 9 & $\mathrm{M}$ & 51.8 & Production Manager \\
\hline Respondents' profiles & $\mathrm{B}$ & 6 & MP & 5.4 & Planning and Scheduling Manager \\
\hline
\end{tabular}

Table 1.

Respondents' profiles 
researchers and following the interview protocol. Interviews were recorded integrally and then transcribed for further analysis. In semi-structured interviews, conversations revolve around a set of topics identified in the agenda and may also touch not predetermined issues (Adams, 2015). This allows us to have enough flexibility to explore the respondent's opinions about complex and interrelated issues, particularly relevant for the final purpose of the study. The first round lasted between 60 and $90 \mathrm{~min}$. To cope with the low depth of cases and to prevent it from undermining the internal validity of the study, all data gathered were then integrated and compared with a second-round interview with the same expert, lasted around $60 \mathrm{~min}$, information coming from direct observation during sites visits, secondary sources as companies publications. This procedure allows to further triangulate information from different sources and to gain "between method triangulation" (Jick, 1979). At last, after conducting the interviews and the analysis, findings regarding their case were critiqued with the experts to increase the interpretation validity.

\subsection{Data analysis}

Contents were coded independently by three different researchers to reduce potential bias that could influence the validity and significance of our results. We followed a mixed approach for coding activity with the final aim to develop a list of broader themes, categories and concepts and to create linkages between them. We used both the deductive approach, defining codes $a$ priori based on scientific literature and the inductive approach, where codes emerge inductively from empirical data as significant themes (Campbell et al., 2013). Through an iterative process of comparison and understanding among the researchers, the relevant codes were detected, and they are available in the following table.

Furthermore, to guarantee the validity and reliability of our study, we strictly considered construct validity, internal and external validity and reliability as metrics (Yin, 2014). Construct validity is ensured by the use of multiple sources of data collected. In detail, secondary sources, company publications, direct observation and two-rounds interviews with experts were considered. Regarding internal validity, we acted on proper analysis and explanation of the relationships between variables and the final outcome. External validity considers the boundaries within which the obtained results can be generalized, and in this study, it is guaranteed by the use of the replication logic. Eventually, repeatability of the study, defined as reliability, is prosecuted by the rigorous use of case study protocol and by the development of a case study database. This database includes all information and data collected during the research in the form of field notes, case study documents and tabular materials.

For the scope of this research, data analysis is done in two stages: a within-case analysis and a cross-case analysis (Eisenhardt, 1989). The within-case analysis allows us to pinpoint a specific digital transformation pattern for each of the two clusters. In the second stage, crosscase analysis is performed to detect and examine diversities and similarities between the digital transformation patterns of the two clusters, to enhance the generalizability of the conclusions (see Table 2). Table 3 summarizes cases and behaviors of the two clusters, as well as of 19 companies along the four different areas studied.

Eventually, we depicted a framework of two different digital transformation patterns resulting from our case studies. For increasing the framework validity and generalizability, results were discussed with experts not included in the sample and with more than 10 years of experience in operations management (Roy et al., 2011). They stressed how this framework is useful for companies to understand a phenomenon that is still blurry and characterized by a high degree of uncertainty. Nevertheless, we believe that by showcasing the two patterns framework, a company might reflect on the strategic choice of digital investments.
How to shape
digital
transformation 
JMTM 32,9

\section{6}

Table 2.

Codes definition

\begin{tabular}{llll}
\hline & Variables & Definition & Source \\
\hline Adopted I4.0 & Adopted Industry 4.0 & Industrial Internet of Things, Industrial & Tortorella and \\
technologies & technologies & $\begin{array}{l}\text { Analytics, Advanced Human-Machine } \\
\text { Interface, Cloud Manufacturing, Additive }\end{array}$ & Fetterman (2018)
\end{tabular}

Manufacturing Advanced Automation

(Tortorella and Fettermann, 2018)

Industry 4.0 Monitoring, Control, Optimization,

technologies maturity

Drivers for I4.0

Industry 4.0

target areas

Industry 4.0

investment drivers

Autonomy

Processing, Assembly, Logistics and

Product development

Increasing production capacity, Outdated

machinery substitution, Governmental

incentives, Improving waste detection, and

Enhancing data availability

Expected Industry 4.0

performance

improvement

Productivity (Parham, 2002), Efficiency

(Lee and Johnson, 2013), Quality

(Chandrupatla, 2009), Time (Bayo-Moriones and De-Cerio, 2002), Flexibility (Gerwin, 1987)

Fettermann et al.

(2018)

Slack et al. (2013)

Within case

Within case

Long pay-back time (higher than 3 years),

Industry 4.0

investments pay-back

time

of I4.0

investments

Industry 4.0 width of intervention

Medium pay-back time (ranging from 2 to 3

years), Short pay-back time (lower than 2

years), Not available

Localized (small interventions areas) and

Extensive (wider interventions areas, e.g. an entire production department or the whole plant)

People and I4.0 Role and task evolution

Substitution (replacement of operators), Control (control of operations), No major changes, Support (ease activities for operators), Enhancement (operators become in charge of making decisions and performing basic problem-solving activities on data)

Competences evolution
Slack et al. (2013)

Within case

Within case

Within case. Marengo (2019);

Flores et al. (2020) Learning capacity, Responsibility,

Teamwork, No major changes

\section{Research results}

Across the 19 companies, it emerges that companies are generally well aware of the various I4.0 technologies and that many implementations are already underway in their respective organizations. In this section, we outline the main findings that emerged from the case studies, by triangulating and merging information from two-round interviews, direct observation and companies' publications. The following Table 3 summarizes the results gathered from the 19 companies along the four different areas studied. More details will be provided in the following subsections.

\subsection{Adopted Industry 4.0 technologies}

I4.0 is a technology-driven paradigm where various and diverse technological applications are included (Benitez et al., 2020; Ivanov et al., 2018; Osterrieder et al., 2020).

Cluster A companies are mostly focused on the implementation of Industrial Internet of Things and Industrial Analytics, which are the mainstay of I4.0. Only a few companies are instead using other technologies, such as Advanced Human-Machine Interface or Cloud 


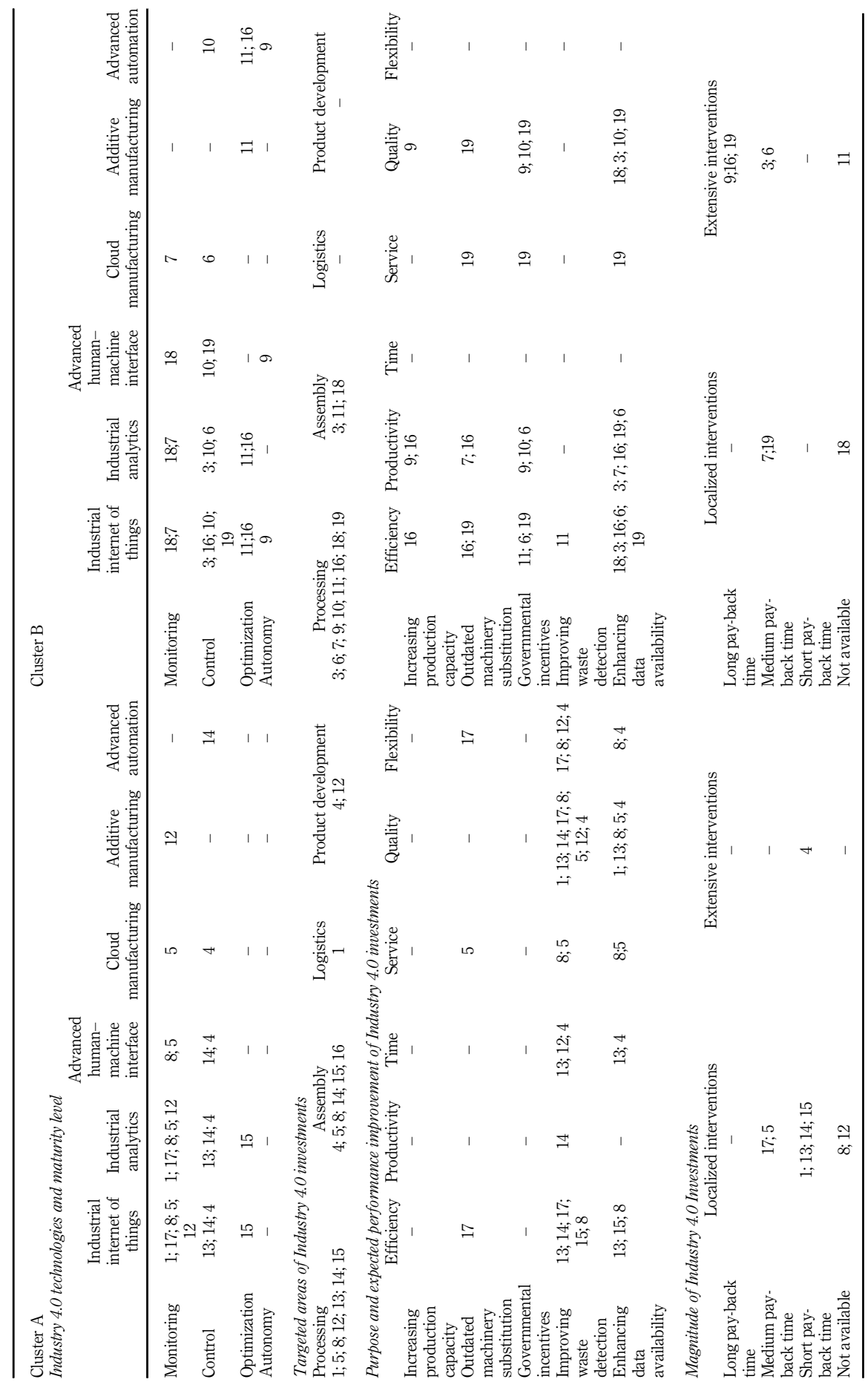

How to shape digital transformation

247

Table 3. Research results 
JMTM 32,9

248 manufacturing. More in detail, according to the framework proposed by Fettermann et al. (2018), Cluster A shows a general lack of maturity regarding I4.0 technologies implementation. The high majority of companies belong to the Monitoring and Control maturity level, having just recently launched their digital initiatives. As confirmed by the literature, since the maturity process is an incremental one and each level is dependent on the one preceding it, we will probably need some years to reach the higher maturity levels: Optimization and Autonomy (Rosin et al., 2020).

Cluster B does not reveal a significant difference in the choice of technologies application compared to Cluster A. Indeed, I4.0 technologies most in vogue here are still Industrial Internet of Things and Industrial Analytics. However, we see a small number of companies implementing both Advanced Human-Machine Interface and Advanced Automation. Regarding the Fetterman et al. (2018) framework, companies belonging to Cluster B exhibit a higher level of I4.0 maturity. Indeed, even if the majority of companies are still under the Monitoring and Control phases, three reached the Optimization and Autonomy level.

The type of I4.0 technology adopted and the frequency of adoption are very similar between the two clusters. Industrial Internet of Things and Industrial Analytics act as the keystone of digital transformation being implemented by almost all companies in our sample while Cloud Manufacturing, Additive Manufacturing or Advanced Automation are adopted just in few cases, being less mature (Boer et al., 2017). Advanced Human-Machine Interface is the most growing technology according to the quite high adoption rate among companies under analysis. Indeed, the socio-technical transformation toward the smart factory will need new design reference models according to new human-centric perspective; in this case, monitoring the workers' performances could provide useful data to improve the humanmachine interaction (Peruzzini et al., 2020). Also, for the I4.0 maturity, the two clusters behave similarly, with most companies showing a low I4.0 maturity level. Therefore, we can conclude that the digital transformation patterns of the two clusters are not differential for what regards either technologies adopted or I4.0 maturity.

\subsection{Drivers for Industry 4.0 implementation}

According to the coding analysis performed, there are three main areas related to the drivers for I4.0 implementations: the targeted areas for implementation, the purpose of the implementation and the expected performance improvement.

Cluster A presents most I.40 implementations within the assembly and processing departments. Few implementations outside production departments are present, namely Logistics and Product Development. On the other hand, Cluster B presents a strong focus on I4.0 implementations within the processing department. Comparing the two clusters, most of I4.0 implementations are within the production department boundaries, but it is noticeable that Cluster A shows more investment outside the processing department. Moreover, Cluster A implemented I4.0 technologies involving simultaneously at least two different areas, showing the horizontal vein of I4.0 investments. It supports the part of operations management literature that presents LP companies easier context for digital transformation than NO-LP companies (Rossini et al., 2019b; Tortorella et al., 2019; Tortorella and Fettermann, 2018) and highlights that the typical holistic view of LP drives I4.0 implementation for enhancing connections among different departments. The focus, for now, is majorly concentrated on the focal firm that is aligned with the literature, but it is worth mentioning that a new stream has emerged investigating the possibility to extend throughout the entire supply chain the implementation of Industry 4.0 (Núñez-Merino et al., 2020).

Regarding the purpose of implementation, Cluster A is characterized by the desire to have higher availability of data and the possibility to tackle wastes. Thanks to I4.0 technologies such as sensors and the Industrial Internet of Things, companies capture a very large amount 
of additional data. While some companies would record real-time information within the production flows to ensure the process to be under control and to promptly communicate with their customers, other companies would monitor pivotal parameters such as the temperature inside a piece of machinery or the wear of a tool to solve quality-related problems or to prevent breakdowns. Differently, Cluster B has a more spread set of drivers, without a unique focus. While most of the companies belonging to Cluster B consider the higher availability of data as the main driver as Cluster A, many others state that financial benefits led by governmental incentives are the main reason to embark upon digital transformation. Furthermore, only a few companies belonging to Cluster B exploit I4.0 technologies to improve their production capacity to cope with an increase in demand volume.

Cluster A implementations are mainly driven by the possibility to enhance both data gathering and data analysis, which are fundamental, and sometimes the bottleneck, activities for continuous improvement initiatives. This is strictly related to LP, and I4.0 technologies are here seen as a way to improve the operations system knowledge and increase the potentialities of a continuous improvement circle. Although it does not have statistical validity, it is noticeable that only Cluster B considers purposes such as Increasing production capacity or governmental incentives. Especially for governmental incentives, all companies belonging to Cluster A point out the fact that investment and implementation (already done or scheduled) are mostly independent of governmental incentives, while they are essential to some companies of Cluster B.

When we investigated whether the digital transformation is driven by specific performance improvements and if we could detect meaningful differences between clusters, we noted that companies usually aspire to more than one performance improvement while implementing I4.0. Cluster B highlights a strong focus on improving efficiency and productivity performance, since, citing Company 7 , thanks to digitalization, the same company and production process will generate greater output. On the other hand, for example, Company 8 belonging to Cluster A remarks that digitalization will improve flexibility, especially because operators will learn what happens behind their work, stressing a general similarity with other companies belonging to Cluster $\mathrm{A}$, as they undertake a digital transformation also to improve quality, time and flexibility performance.

\subsection{Magnitude of industry 4.0 investments}

The magnitude of I4.0 investments refers to the extent of digital investments enabling the digital transformation of a company.

Cluster A prioritizes investments that can be repaid in the short run, usually lower than 2 years, with almost all in favor of localized interventions, by targeting small portions of the process. This is in line with LP, which encourages small and short projects to foster the learning cycle. Company 15 underlines that the key to their successful digital transformation can be seen in the step-by-step approach, where spread and wide changes are avoided to reduce any problem. In contrast, Cluster B companies mostly pursue extensive interventions with medium to long payback time. They tend to develop investment plans characterized by large investments and a wide range of actions. Company 6, for example, is investing at the same time in three different automatic lines and a semi-automatic warehouse. Their interventions usually determine important effects on the whole organization and imply quite longer repayment times compared to companies belonging to Cluster A.

As evident, the two clusters here show antipodal behaviors. While Cluster A is more focused on small and localized digital interventions, Cluster B embraces a more breakthrough vision of digitalization where interventions are extensive, and investments require greater effort from the organization. Considering investment size as a proxy of the size of the change, Cluster A presents a sequence of many small changes aimed at fostering the learning cycle
How to shape
digital
transformation 
JMTM 32,9 and strengthening the digital capability of the company, while Cluster B prefers designing few interventions to make a fast and radical digital transformation.

\subsection{People and Industry 4.0}

The two polar clusters registered a shared insight on demand for advanced IT skills in operators; indeed, operators are required to run digitalized processes and to interact with technological devices effectively (Peruzzini et al., 2020).

In Cluster A, I4.0 technologies support or even enhance operators' work performance: they assist operators in data collection and data analysis. These gathered data will be available in real-time to operators who are thus enabled to take decisions. According to Company 5 , data will empower operators in understanding how the machine works and to make a conscious decision on how to solve problems and eventually improve production. In this cluster, companies recommend important progress in operators regarding problem-solving competencies, learning ability and responsibility. The role of operators results to be enhanced thanks to higher process visibility, new responsibilities and the possibility to focus on value-added activities. This paradigm shift surely requires a change in operators' competencies that can only be reached with an appropriate approach to training and qualification. On the opposite, Cluster B mainly promotes I4.0 technologies for controlling or substitute operations. The involvement of people is not noticeable, although none of the companies was planning any personnel layoffs. Company 9 , for example, remarks that the introduction of Advanced automation was aimed at guaranteeing production reliability, which was not possible relying only on operators or human work.

Unlike Cluster A, Cluster B shows a misalignment with the literature when it comes to the role of people in I4.0 and their importance. While Cluster B is decisively in favor of the presence of technologies against operators, the literature clearly states that it is not about substituting operators; it is about eliminating repetitive tasks done by them and moving from low-level skills to high-level skills (Marengo, 2019). It is argued that decreasing the number of workers in the organizations leads eventually to loss of knowledge, as they can transform data given by I4.0 technologies into knowledge with their cognitive abilities (Sousa and Wilks, 2018). The difference in the perspectives of the two clustered could be highly linked to their culture, hence the adoption of LP principles, which is centered on people, sculpting them into decision-makers and involving them in continuous improvement projects. Such culture eventually allows operators to actively participate in the digital transformation by exploiting the offerings of I4.0 when it comes to real-time data visualization, for example, to help operators in effective decision making (The 2019 World Manufacturing Forum Report, 2019).

The differentiation between the two clusters can be mainly explained by the central role that people have always represented in the LP, which characterizes Cluster A. Company 13 from Cluster A highlights that, since required manual tasks are nowadays much less than in the past, operators need to have greater and completely different skills, especially in terms of IT tools and mental elasticity.

\section{Discussion}

The main aim of our research is to investigate how companies embark upon digital transformation and whether, and in case how, LP plays a role in driving it. According to the previous section, we identified four main areas that uniquely characterize the two polar clusters, leading us to represent two digital transformation patterns. Using terms coined in the innovation area, we call them Sustaining digital transformation pattern, arising from Cluster A, and Disruptive digital transformation pattern, arising from Cluster B. Table 4 summarises features of the two identified digital transformation patterns. 


\begin{tabular}{|c|c|c|c|c|}
\hline & Variables & $\begin{array}{l}\text { Sustaining digital } \\
\text { transformation pattern }\end{array}$ & $\begin{array}{l}\text { Disruptive digital } \\
\text { transformation pattern }\end{array}$ & $\begin{array}{r}\text { How to shape } \\
\text { digital }\end{array}$ \\
\hline $\begin{array}{l}\text { Adopted I4.0 } \\
\text { technologies }\end{array}$ & $\begin{array}{l}\text { Adopted Industry } 4.0 \\
\text { technologies }\end{array}$ & Not differential & Not differential & \\
\hline \multirow[t]{4}{*}{$\begin{array}{l}\text { Drivers for I4.0 } \\
\text { investments }\end{array}$} & $\begin{array}{l}\text { Industry } 4.0 \text { target } \\
\text { areas }\end{array}$ & Spread in all functions & $\begin{array}{l}\text { Focused on machinery and } \\
\text { production processes }\end{array}$ & \\
\hline & Industry 4.0 & Vertical and horizontal & Mainly vertical approach & 251 \\
\hline & & $\begin{array}{l}\text { approach (improve } \\
\text { interdepartmental connections) }\end{array}$ & (single department focused) & \\
\hline & $\begin{array}{l}\text { Expected Industry } 4.0 \\
\text { performance } \\
\text { improvement }\end{array}$ & Quality, time and flexibility & Efficiency, productivity & \\
\hline \multirow[t]{2}{*}{$\begin{array}{l}\text { Magnitude of } \\
\text { I4.0 investments }\end{array}$} & $\begin{array}{l}\text { Industry } 4.0 \\
\text { investments pay-back } \\
\text { time }\end{array}$ & Short payback time & Medium-long payback time & \\
\hline & $\begin{array}{l}\text { Industry } 4.0 \text { width of } \\
\text { intervention }\end{array}$ & Many small and localized & Few complex and extensive & \\
\hline \multirow[t]{3}{*}{ People and I4.0 } & Role and task evolution & Empowering operators, & Enhancing machines, & \\
\hline & & $\begin{array}{l}\text { increasing operators' } \\
\text { contribute and responsibility }\end{array}$ & $\begin{array}{l}\text { decreasing operator } \\
\text { responsibility on the process }\end{array}$ & $\begin{array}{r}\text { Table } 4 . \\
\text { Digital transformation }\end{array}$ \\
\hline & Competences evolution & Not differential & Not differential & patterns compariso \\
\hline
\end{tabular}

Sustaining a digital transformation pattern is typical for companies that show high commitment to LP. Sustaining a digital transformation pattern is characterized by the achievement and consolidation of a series of small and incremental projects. This leads to a short or medium payback time of I4.0 implementation projects and the opportunity, pair-budget conditions, to test different technology types in different areas of the company. Here, digital transformation does not occur only in the production department, but I4.0 implementations are also spread in other departments. Furthermore, even if I4.0 implementations are small and localized, they have a strong horizontal perspective: digital transformation involves more areas at the same time, and it is aimed at improving connection and collaboration among them. The implementations of I4.0 technologies is thus not focused on automatizing operations but rather aims at gathering new data and enhancing analysis system capability to tackle wastes. The underlying nature of these applications determines the enhancement of operators. Indeed, I4.0 implementations are leveraged to push people away from nonvalue-added activities and to provide them with relevant data and room for taking decisions.

As an alternative, a Disruptive digital transformation pattern emerges from companies poorly committed to LP. The Disruptive digital transformation pattern is characterized by a few and large steps toward I4.0 that imply a disruptive and radical change in the company system. Accordingly, this pattern is characterized by I4.0 technologies aimed at faster operations with an increase in production capacity. Digital transformation means here breakthrough projects, with greater investments organized in complex and integrated plans with usually medium/long repayment times. In this context, governmental incentives play a fundamental role in the launch of digital initiatives for achieving the necessary monetary budget. Moreover, I4.0 implementations are vertical and focused on only a single department per project, usually inside the Production department. The underlying thinking of I4.0 implementation is to have more advanced machines: those machines should embrace a larger part of the working activities and should be more "intelligent" to take decisions autonomously without human interference.

Apart from the I4.0 technologies adopted, the two digital transformation patterns are strongly different. In line with the literature that showed a significant link between I4.0 and 
JMTM 32,9

252

LP (Marodin et al., 2019; Rossini et al., 2019b), Sustaining a digital transformation pattern is strongly shaped by LP. Indeed, LP influences the way how I4.0 technologies are introduced in companies operations systems: the smallness and shortness of a project reflect the LP of having short-runs of system improvement, passing through pilot projects and then spreading of the new standards to the other parts of the system (Ohno, 1988). Moreover, the horizontal vein of digital transformation is a natural consequence of LP that incentivizes the holistic view of the operations system (Piercy and Rich, 2015). The exploitation of I4.0 for enhancing operators' decisional capability, and so delegating the decisional process to a more operative level, is perfectly aligned with the human-centric vision of LP systems (Womack et al., 1990; Womack and Jones, 2003). On the other side, the Disruptive digital transformation pattern presents features that appear far from the LP paradigm (e.g. big size and long breakthrough project, implementation led by opportunistic context, very vertical approach). The Disruptive digital transformation pattern is a pathway in contrast with LP.

The framework in Figure 2 depicts the two digital transformation patterns emerging from the study. The framework considers three main dimensions: LP implementation level, I4.0 implementation level and the extent to which digitalization pervades the company. The first two dimensions are represented by the two axes: the higher the bullet position, the higher the I4.0 implementation within the company; while the more the bullet is on the right of the framework, the higher the company commitment to LP. The third dimension exploits the colors of the bullets, where the darker the bullet color, the higher the degree of horizontality of digitalization within the company (in terms of the number of departments or processes involved in the digital transformation).

Arrows stand for the path a company may pursue to increase its digitalization level.

With Sustaining digital transformation pattern, companies look at I4.0 not only as an opportunity for introducing new technologies but even as an opportunity for pushing their LP mission further. Then, LP plays a strong role in driving the digital transformation of a company. First, LP shapes the way I4.0 technologies are introduced in the operations system: namely, small and incremental changes, strong involvement of people and horizontal implementations. The several and incremental steps that compose Sustaining digital transformation pattern are a series of learning cycles that the company develops. LP drives digital transformation to make the integration of I4.0 technologies within the company easier by giving the right time to stakeholders to understand their potentialities and find their way to exploit them. At each cycle, the company understands better I4.0 technologies, consolidates the knowledge and spreads it through other areas of the organization.

The insight of this framework is aligned with the past literature about the interplay of lean and I4.0, but it adds an important step to our understanding of how the two paradigms interact with each other. This study confirms and reinforces the positive relationship between lean and

Figure 2.

Digital transformation patterns

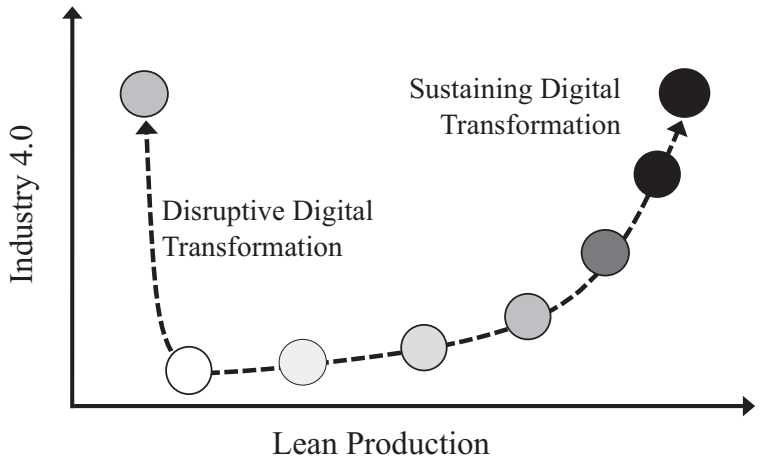


I4.0 (Buer et al., 2020). Moreover, it enhances the literature that presents lean supporting I4.0 (Ciano et al., 2020) because the framework clearly defines how lean drives digital transformation, how it configures and how it spreads I4.0 technologies through the factory.

\section{Conclusions}

While there is hype on I4.0 nowadays, it is surprising that a central question related to the digital transformation is not adequately addressed yet. How companies embark upon digital transformation patterns is still an open issue, as well as how being lean may affect it. Our study is one of the first empirical studies to contribute to this nascent debate by understanding the main patterns of digital transformation. Our main findings show that companies with a strong commitment to LP shape their digital transformation patterns differently compared to companies that are poorly committed to LP. A clear pattern that guides the digital transformation is a critical success factor to transform opportunities from I4.0 into a competitive advantage. Both practitioners and scholars need to know what to expect. We name the two different digital transformation patterns as Sustaining digital transformation pattern, where digitalization is made by small steps, and it involves the whole company in a horizontal way, and Disruptive digital transformation pattern, where big digital investments occur with a more vertical focus.

\subsection{Theoretical contribution}

Several experts declared that LP must be considered as a prerequisite or enabler for the digital transformation (see, for example, Davies et al., 2017; Dombrowski and Richter, 2018; Prinz et al., 2018), but this statement is still under discussion. Our study empirically contributes to this debate, showing that I4.0 and LP cannot be considered as two independent factors. Indeed, a company highly committed to LP shapes differently its digital transformation pattern, which is characterized by features typical of lean.

Thanks to performed case studies, we postulate that LP directly influences I4.0 technologies implementation shaping a different digital transformation pattern. This could explain the scientific literature stating that LP companies achieve better results in digitalization than companies poorly committed with lean. Companies that are deeply implementing LP and its culture are driving a different digital transformation pattern that may lead to better performance, and thus, to a more successful I4.0 technology implementation (Buer et al., 2018; Rossini et al., 2019a).

The final framework developed is a synthesis of the results coming from the two polar clusters. It represents two different transformation patterns, namely Sustaining digital transformation pattern and Disruptive digital transformation pattern. This framework can be considered as a basis upon which future researchers of digital transformation can take their steps. Nevertheless, the multiple case study method represents a novelty if we look at studies already published on this topic: this research also brings a new methodology approach to this specific field of investigation. Researchers highlighted that I4.0 technologies in an LP company contribute to improving its operational performances, from productivity to quality to lead time reduction, at a higher rate with respect to applying LP or I4.0 alone (Kamble et al., 2020; Moeuf et al., 2018; Rossini et al., 2019b; Tortorella and Fettermann, 2018). Such greater improvements compared to companies with no LP commitment may be imputable to the Sustaining digital transformation, typical of LP companies and is strictly different from other types of companies.

\subsection{Managerial contribution}

This paper has extended the knowledge regarding the relationships between I4.0 and lean. By starting from a robust empirical analysis, our findings provide indications for managers 
JMTM 32,9 regarding how companies could embrace digital transformation. Thus, the digital transformation represents for managers both a new opportunity for investment and innovation and a challenge to remain competitive in the modern dynamic environment. Unfortunately, up to date, there are still doubts and misconceptions around I4.0, and companies struggle in successfully embarking upon digital transformation. Furthermore, managers can use the framework and the associated results to benchmark themselves against other companies with similar characteristics.

Our research indeed provides a useful framework for the successful implementation of I4.0 technologies, especially for manufacturing companies working within a low-volume wider variety. However, some of the findings may be valuable also for similar companies based in other industries. Managers should seek out approaching lean to increase the chances to have a faster and more robust digital transformation. Companies can benefit from our framework not only while evaluating their start-up investments in I4.0 but also when they have already invested in such technologies and want to understand how to go further. Moreover, this research adds an important piece of knowledge to practitioners to understand with a practical perspective the meaning of combining lean paradigm with the I4.0 technologies.

\subsection{Limitations and future research}

This research implies some limitations that should be highlighted both for clarity and as input for future research on this topic.

The multiple case study research method entails a set of shortcomings. One of the main concerns is related to the generalization of results. A future research opportunity is thus to seek empirical validation of these results in a study with a larger sample. Moreover, while defining the digital transformation pattern, we focus our attention on four main areas of digital transformation. While we neglected on purpose other variables that can influence the companies behavior, some of these could affect companies as external market conditions, macroeconomic situations, or specific cost-benefit analyses. An attempt to reduce the impact of this limitation was made by considering a set of companies as similar as possible, but further studies are necessary for a better understanding of phenomena. Moreover, Industry 4.0 is still a novel and dynamic trend, with rapid developments and new solutions proposed. Then, we see the value of follow-up studies to determine if the relationships investigated in this study will change over time.

Furthermore, this research provides several starting points for future studies. First, the same multiple case study can be replicated with a different set of companies, especially with high-volume and low-variety companies, trying to detect possible differences between the two panel of companies. A second possible replication can be performed with companies based in a different country, for instance, in a developing country, since also, in this case, relevant differences may emerge. As mentioned, the same study can also be enriched by considering further characteristics of the companies behavior in terms of digital transformation. Eventually, new research could consider a more disaggregated categorization of I4.0 technologies that could lead to unveiling further differentiation between companies' digital transformation according to their LP maturity levels.

Further promising research should link the different interpretations of digital transformation at the supply chain level and its link with lean. Beyond the single firm boundaries, the influence of lean on the digital transformation of suppliers and customers could be an important topic to investigate to exploit as much as possible I4.0 potentials. It is expected that organizations will be strongly hit by these changes at all levels of the supply chain. With the help of the researchers, factories could have a better understanding of how the "digitalization" of their supply chain partners affects their position, their operations and the way they manufacture. 


\section{References}

Adams, W.C. (2015), "Conducting semi-structured interviews", in Handbook of Practical Program Evaluation, 4th ed., pp. 492-505.

Alcácer, V. and Cruz-Machado, V. (2019), "Scanning the Industry 4.0: a literature review on technologies for manufacturing systems", Engineering Science and Technology, an International Journal, Vol. 22 No. 3, pp. 899-919.

Bayo-Moriones, A. and De-Cerio, J.M.-D. (2002), "Human resource management, strategy and operational performance in the Spanish manufacturing industry", Management, Vol. 5, p. 175.

Benitez, G.B., Ayala, N.F. and Frank, A.G. (2020), "Industry 4.0 innovation ecosystems: an evolutionary perspective on value cocreation", International Journal of Production Economics, Vol. 228, doi: 10.1016/j.ijpe.2020.107735.

Boer, H., Berger, A., Chapman, R. and Gertsen, F. (2017), CI Changes from Suggestion Box to Organisational Learning: Continuous Improvement in Europe and Australia, Taylor and Francis, doi: 10.4324/9781315198286.

Brennan, L., Ferdows, K., Godsell, J., Golini, R., Keegan, R., Kinkel, S., Srai, J.S. and Taylor, M. (2015), "Manufacturing in the world: where next?", International Journal of Operations and Production Management, Vol. 35 No. 9, pp. 1253-1274.

Bryman, A. (2012), Social Research Methods, Oxford University Press, New York.

Buer, S.V., Strandhagen, J.O. and Chan, F.T.S. (2018), "The link between Industry 4.0 and lean manufacturing: mapping current research and establishing a research agenda", International Journal of Production Research, Vol. 56 No. 8, pp. 2924-2940.

Buer, S.V., Strandhagen, J.W., Semini, M. and Strandhagen, J.O. (2020), "The digitalization of manufacturing: investigating the impact of production environment and company size", Journal of Manufacturing Technology Management, 247637, doi: 10.1108/JMTM-05-2019-0174.

Cagliano, R., Canterino, F., Longoni, A. and Bartezzaghi, E. (2019), "The interplay between smart manufacturing technologies and work organization: the role of technological complexity", International Journal of Operations and Production Management, Vol. 39 No. 2, pp. 913-934.

Campbell, J.L., Quincy, C., Osserman, J. and Pedersen, O.K. (2013), "Coding in-depth semistructured interviews: problems of unitization and intercoder reliability and agreement", Sociological Methods and Research, Vol. 42 No. 3, pp. 294-320.

Chandrupatla, T.R. (2009), "Quality concepts", in Quality and Reliability in Engineering, s.1., Cambridge.

Chiarini, A., Belvedere, V. and Grando, A. (2020), "Industry 4.0 strategies and technological developments", in An Exploratory Research from Italian Manufacturing Companies, Production Planning and Control, Taylor and Francis, doi: 10.1080/09537287.2019.1710304.

Ciano, M.P., Dallasega, P., Orzes, G. and Rossi, T. (2020), "One-to-one relationships between Industry 4.0 technologies and lean manufacturing techniques: a multiple case study”, International Journal of Production Research, pp. 1-25.

Culot, G., Nassimbeni, G., Orzes, G. and Sartor, M. (2020), "Behind the definition of Industry 4.0: analysis and open questions", International Journal of Production Economics, Elsevier B.V, doi: 10.1016/j.ijpe.2020.107617.

Davies, R., Coole, T. and Smith, A. (2017), "Review of socio-technical considerations to ensure successful implementation of Industry 4.0”, Procedia Manufacturing, Vol. 11, pp. 1288-1295.

Dombrowski, U. and Richter, T. (2018), "The lean production system 4.0 framework - enhancing lean methods by Industrie 4.0", IFIP Advances in Information and Communication Technology, pp. $410-416$.

Eisenhardt, K.M. (1989), "Building theories from case study research", Academy of Management Review, Vol. 14 No. 4, pp. 532-550.

Erol, S., Jäger, A., Hold, P., Ott, K. and Sihn, W. (2016), "Tangible Industry 4.0: a scenario-based approach to learning for the future of production", Procedia CIRP, pp. 13-18.
How to shape
digital
transformation

255 
JMTM 32,9
Fettermann, D.C., Cavalcante, C.G.S., de Almeida, T.D. and Tortorella, G.L. (2018), "How does Industry 4.0 contribute to operations management?", Journal of Industrial and Production Engineering, Vol. 35 No. 4, pp. 255-268.

Flores, E., Xu, X. and Lu, Y. (2020), "Human capital 4.0: a workforce competence typology for industry 4.0", Journal of Manufacturing Technology Management, Vol. 31 No. 4, pp. 687-703.

Forbes India (2020), "Information technology: the vital $\operatorname{cog}$ in the wheel of digital transformation", Forbes India.

Frank, A.G., Dalenogare, L.S. and Ayala, N.F. (2019), "Industry 4.0 technologies: implementation patterns in manufacturing companies", International Journal of Production Economics, Elsevier B.V., Vol. 210, pp. 15-26.

Gerwin, D. (1987), "An agenda for research on the flexibility of manufacturing processes", International Journal of Operations and Production Management.

Ghobakhloo, M. and Fathi, M. (2020), "Corporate survival in Industry 4.0 era: the enabling role of leandigitized manufacturing”, Journal of Manufacturing Technology Management, Vol. 31 No. 1, pp. 1-30.

Gillani, F., Chatha, K.A., Sadiq Jajja, M.S. and Farooq, S. (2020), "Implementation of digital manufacturing technologies: antecedents and consequences", International Journal of Production Economics, Elsevier B.V., Vol. 229, doi: 10.1016/j.ijpe.2020.107748.

Gioia, D.A., Corley, K.G. and Hamilton, A.L. (2013), "Seeking qualitative rigor in inductive research: notes on the Gioia methodology", Organizational Research Methods, Vol. 16 No. 1, pp. 15-31.

Hambach, J., Kümmel, K. and Metternich, J. (2017), "Development of a digital continuous improvement system for production”, Procedia CIRP, Vol. 63, pp. 330-335.

Ivanov, D., Das, A. and Choi, T.M. (2018), "New flexibility drivers for manufacturing, supply chain and service operations", Taylor and Francis, International Journal of Production Research, Vol. 56 No. 10, pp. 3359-3368.

Jick, T.D. (1979), "Mixing qualitative and quantitative methods: triangulation in action", Administrative Science Quarterly, Vol. 24 No. 4, pp. 602-611.

Kamble, S., Gunasekaran, A. and Dhone, N.C. (2020), "Industry 4.0 and lean manufacturing practices for sustainable organisational performance in Indian manufacturing companies", International Journal of Production Research, Vol. 58 No. 5, pp. 1319-1337.

Ketokivi, M. and Choi, T. (2014), "Renaissance of case research as a scientific method", Journal of Operations Management, Vol. 32 No. 5, pp. 232-240.

Koh, L., Orzes, G. and Jia, F. (2019), "The fourth industrial revolution (Industry 4.0): technologies disruption on operations and supply chain management", International Journal of Operations and Production Management, Vol. 39 Nos 6/7/8, pp. 817-828.

Kolberg, D. and Zühlke, D. (2015), "Lean automation enabled by industry 4.0 technologies", IFACPapersOnLine, Vol. 28 No. 3, pp. 1870-1875.

Lasi, H., Fettke, P., Kemper, H.G., Feld, T. and Hoffmann, M. (2014), "Industry 4.0", Business and Information Systems Engineering, Vol. 6 No. 4, p. 239.

Lee, C.-Y. and Johnson, A.L. (2013), "Operational efficiency", in Badiru, A.B. (Ed.), Handbook of Industrial and Systems Engineering, CRC Press, Cambridge, pp. 17-44.

Liao, Y., Deschamps, F., Loures, E.D.F.R. and Ramos, L.F.P. (2017), "Past, present and future of Industry 4.0 - a systematic literature review and research agenda proposal", International Journal of Production Research, Vol. 55 No. 12, pp. 3609-3629.

Lugert, A., Batz, A. and Winkler, H. (2018), "Empirical assessment of the future adequacy of value stream mapping in manufacturing industries", Journal of Manufacturing Technology Management, Vol. 29 No. 5, pp. 886-906.

Marengo, L. (2019), "Is this time different? A note on automation and labour in the fourth industrial revolution", Journal of Industrial and Business Economics, Springer, Vol. 46 No. 3, pp. 323-331. 
Marodin, G.A., Frank, A.G., Tortorella, G.L. and Fetterman, D.C. (2019), "Lean production and operational performance in the Brazilian automotive supply chain”, Total Quality Management and Business Excellence, Vol. 30 Nos 3-4, pp. 370-385.

Matt, C., Hess, T. and Benlian, A. (2015), "Digital transformation strategies”, Business and Information Systems Engineering, Springer Fachmedien Wiesbaden, Vol. 57 No. 5, pp. 339-343.

Mayr, A., Weigelt, M., Kühl, A., Grimm, S., Erll, A., Potzel, M. and Franke, J. (2018), "Lean 4.0 - a conceptual conjunction of lean management and Industry 4.0”, Elsevier B.V., Procedia CIRP, Vol. 72 , pp. 622-628.

Mexican Ministry of Economy (2016), Crafting the Future: A Roadmap for Industry 4.0 in Mexico, Mexican Ministry of Economy, doi: 10.3109/10715762.2013.812785.

Mittal, S., Khan, M.A., Romero, D. and Wuest, T. (2018), "A critical review of smart manufacturing and Industry 4.0 maturity models: implications for small and medium-sized enterprises (SMEs)", Journal of Manufacturing Systems, Vol. 49, pp. 194-214.

Moeuf, A., Pellerin, R., Lamouri, S., Tamayo-Giraldo, S. and Barbaray, R. (2018), "The industrial management of SMEs in the era of Industry 4.0", International Journal of Production Research, Taylor and Francis, Vol. 7543, pp. 1118-1136.

Motyl, B., Baronio, G., Uberti, S., Speranza, D. and Filippi, S. (2017), "How will change the future engineers' skills in the Industry 4.0 framework? A questionnaire survey", Procedia Manufacturing, Vol. 11, pp. 1501-1509.

National Confederation of Industry (2016), Challenges for Industry 4.0 in Brazil, CNI.

Netland, T.H. and Ferdows, K. (2016), “The S-curve effect of lean implementation”, Production and Operations Management, Vol. 25 No. 6, pp. 1106-1120.

Núñez-Merino, M., Maqueira-Marín, J.M., Moyano-Fuentes, J. and Martínez-Jurado, P.J. (2020), "Information and digital technologies of Industry 4.0 and lean supply chain management: a systematic literature review", International Journal of Production Research, Taylor and Francis, Vol. 58 No. 16, pp. 5034-5061.

Ohno, T. (1988), Toyota Production System: Beyond Large-Scale Production, Productivity Press, Portland.

Osterrieder, P., Budde, L. and Friedli, T. (2020), "The smart factory as a key construct of Industry 4.0: a systematic literature review", International Journal of Production Economics, Elsevier B.V., Vol. 221, doi: 10.1016/j.ijpe.2019.08.011.

Pagliosa, M., Tortorella, G. and Ferreira, J.C.E. (2019), "Industry 4.0 and lean manufacturing: a systematic literature review and future research directions", Journal of Manufacturing Technology Management. doi: 10.1108/JMTM-12-2018-0446.

Parham, D. (2002), "Definition, importance and determinants of productivity", Deepa Economics, s.l.

Peruzzini, M., Grandi, F. and Pellicciari, M. (2020), "Exploring the potential of operator 4.0 interface and monitoring", Computers and Industrial Engineering, Elsevier, Vol. 139, doi: 10.1016/j.cie. 2018.12.047.

Pessot, E., Zangiacomi, A., Battistella, C., Rocchi, V., Sala, A. and Sacco, M. (2020), "What matters in implementing the factory of the future: insights from a survey in European manufacturing regions", Journal of Manufacturing Technology Management. doi: 10.1108/JMTM-05-2019-0169.

Piercy, N. and Rich, N. (2015), "The relationship between lean operations and sustainable operations", International Journal of Operations and Production Management, Vol. 35 No. 2, pp. 282-315.

Prinz, C., Kreggenfeld, N. and Kuhlenkötter, B. (2018), "Lean meets Industrie 4.0 - a practical approach to interlink the method world and cyber-physical world", Procedia Manufacturing, pp. 21-26.

Quezada, L.E., Chiu, A.S.F., Gouvea da Costa, S.E. and Tan, K.H. (2017), "Operational excellence towards sustainable development goals through Industry 4.0", International Journal of Production Economics, Vol. 190, pp. 1-2.

Rencher, A.C. and William, F.C. (2012), Methods of Multivariate AnalysisMethods of Multivariate Analysis, 3rd ed., doi: 10.1002/9781118391686. 
JMTM 32,9

Rosin, F., Forget, P., Lamouri, S. and Pellerin, R. (2020), "Impacts of Industry 4.0 technologies on lean principles", International Journal of Production Research, Taylor and Francis, Vol. 58 No. 6, pp. 1644-1661.

Rossini, M., Costa, F., Portioli-Staudacher, A. and Tortorella, G.L. (2019a), "Industry 4.0 and lean production: an empirical study", IFAC-PapersOnLine, Vol. 52 No. 13, pp. 42-47.

Rossini, M., Costa, F., Tortorella, G.L. and Portioli-Staudacher, A. (2019b), "The interrelation between Industry 4.0 and lean production: an empirical study on European manufacturers", International Journal of Advanced Manufacturing Technology, Vol. 102 Nos 9-12, pp. 3963-3976.

Roy, R., Souchoroukov, P. and Shehab, E. (2011), "Detailed cost estimating in the automotive industry: data and information requirements", International Journal of Production Economics, Vol. 133 No. 2, pp. 694-707.

Sanders, A., Elangeswaran, C. and Wulfsberg, J. (2016), "Industry 4.0 implies lean manufacturing: research activities in Industry 4.0 function as enablers for lean manufacturing", Journal of Industrial Engineering and Management, Vol. 9 No. 3, pp. 811-833.

Sanders, A., K Subramanian, K.R., Redlich, T. and Wulfsberg, J.P. (2017), "Industry 4.0 and lean management - synergy or contradiction?", IFIP Advances in Information and Communication Technology, Vol. 514, pp. 341-349.

Shah, R. and Ward, P.T. (2007), "Defining and developing measures of lean manufacturing", Journal of Operations Management, Vol. 25 No. 4, pp. 785-805.

Slack, N., Brandon-Jones, A. and Johnston, R. (2013), Operations Management, 7th ed., s.l., Pearsons Education.

Sony, M. (2018), "Industry 4.0 and lean management: a proposed integration model and research propositions", Production and Manufacturing Research, Vol. 6 No. 1, pp. 416-432.

Sousa, M.J. and Wilks, D. (2018), "Sustainable skills for the world of work in the digital age", Systems Research and Behavioral Science, John Wiley and Sons, Vol. 35 No. 4, pp. 399-405.

Tortorella, G.L. and Fettermann, D. (2018), "Implementation of Industry 4.0 and lean production in Brazilian manufacturing companies", International Journal of Production Research, Vol. 56 No. 8, pp. 2975-2987.

Tortorella, G.L., Giglio, R. and van Dun, D.H. (2019), "Industry 4.0 adoption as a moderator of the impact of lean production practices on operational performance improvement", International Journal of Operations and Production Management, Vol. 39 No. 2, pp. 860-886.

Voss, C., Tsikriktsis, N. and Frohlich, M. (2002), "Case research in operations management", International Journal of Operations and Production Management, Vol. 22 No. 2, pp. 195-219.

Wagner, T., Herrmann, C. and Thiede, S. (2017), "Industry 4.0 impacts on lean production systems", Procedia CIRP, Vol. 63, pp. 125-131.

Womack, J.P. and Jones, D.T. (2003), Lean Thinking: Banish Waste and Create Wealth in Your Corporation, Free Press, Simon \& Schuster, New York.

Womack, J.P., Johnes, D.T. and Roos, D. (1990), The Machine that Changed the World, Free Press, New York, doi: 10.5860/choice.28-4589.

World Manufacturing Forum (2019), The 2019 World Manufacturing Forum Report, World Manufacturing Forum.

Yin, R.K. (2014), Case Study Research: Design and Methods, 5th ed., Sage Publications, Thousand Oaks, California.

\section{Further reading}

Lööw, J., Abrahamsson, L. and Johansson, J. (2019), "Mining 4.0 - the impact of new technology from a workplace perspective", Mining Engineering, Society for Mining, Metallurgy and Exploration, Vol. 71 No. 12, pp. 47-48. 
Appendix

\begin{tabular}{|c|c|}
\hline Topic & Main question \\
\hline $\begin{array}{l}\text { I4.0 } \\
\text { investment }\end{array}$ & $\begin{array}{l}\text { How much did you invest in Industry } 4.0 \\
\text { technologies? How much do you plan to } \\
\text { invest in the future? } \\
\text { Did you exploit some government incentives? } \\
\text { If yes, which ones? } \\
\text { What was the role of incentives in investment } \\
\text { decisions? }\end{array}$ \\
\hline & $\begin{array}{l}\text { What is the expected PBT of the investment? } \\
\text { What is the expected return of the } \\
\text { investment? } \\
\text { What is the investment focus? What is its } \\
\text { allocation (hardware, software, people. . .)? }\end{array}$ \\
\hline $\begin{array}{l}\text { I4.0 } \\
\text { technologies }\end{array}$ & $\begin{array}{l}\text { On which technologies have you already } \\
\text { invested? On which one have you planned to } \\
\text { invest in the future? } \\
\text { What is the usage or application for the } \\
\text { introduced technologies? } \\
\text { In which sequence were the technologies } \\
\text { introduced? }\end{array}$ \\
\hline $\begin{array}{l}\text { I.4.0 in the } \\
\text { company }\end{array}$ & $\begin{array}{l}\text { Which is/are the area(s) targeted by the } \\
\text { investments (E.g. logistics, processing, } \\
\text { assembly, product development, } \\
\text { procurement ...)? } \\
\text { What is the reason behind the investment } \\
\text { decision? } \\
\text { Which were the aimed results/benefits of the } \\
\text { investment? }\end{array}$ \\
\hline
\end{tabular}

How has the implementation phase been managed? Have some external consultants been involved?

What was the investment impact on people? How did the work tasks change? Did you introduce a training program?

Lean and I4.0 What is the role played by Lean Production practices in this transformation?

How are you managing Lean and 4.0 transformations?

Do Lean and Industry 4.0 transformations

follow the same logic or not?

How will Lean practices implementation evolve in the future?
Possible follow-up question

What is the rationale behind that choice?

What are the achieved benefits?

Have incentives led to investments that you would not have made otherwise? Have incentives moved up investments?

How was it evaluated?

How was it evaluated?

What are the reasons behind that allocation?

Why did you choose that technology over the others?

Why? How that sequence will continue in the future?

Does the investment involve other entities such as customers and suppliers?

How did you identify the need for introducing I4.0 technologies?

How has the initial plan evolved? Other benefits emerged? Are advantages higher or lower than expected?

Which are the main complexities/ criticalities of the project?

How do you judge the impact of industry 4.0 on the employment level?

What results would you have achieved with a lower Lean maturity level?

Are they sequential or simultaneous? Do

they have interactions?

Are they dependent or independent

phenomena?

Why?
How to shape
digital
transformation

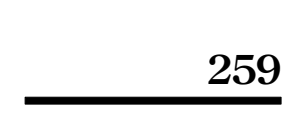

